\title{
THE POTENTIAL OF ROBUSTA COFFEE (COFFEA CANEPHORA) AS A COLORECTAL CANCER THERAPY MODALITY: AN IN SILICO STUDY
}

\author{
DESSY AGUSTINI ${ }^{1 *}$, LEO VERNADESLY ${ }^{1}$, DELVIANA $^{1}$, THEODORUS $^{2}$
}

${ }^{1}$ Medicine Program, Universitas Sriwijaya, Pahlawan, Dokter Muhammad Ali Street, Sekip Jaya, Palembang City, Indonesia. ${ }^{2}$ Department of Pharmacology, Universitas Sriwijaya, Pahlawan, Jalan Dokter Muhammad Ali Street, Sekip Jaya, Palembang City, Indonesia

*Email: dessyagustini2000@gmail.com

Received: 27 June 2021, Revised and Accepted: 20 September 2021

ABSTRACT

Objectives: This research aims to determine the efficacy of compounds in robusta coffee against colorectal cancer through the inhibition of the T-cell immunoglobulin and immunoreceptor tyrosine-based inhibitory motif domain (TIGIT) receptor.

Methods: This in silico study has been conducted in computing platform from June to August 2021. The selected test compounds would go through the Lipinski rule screening through the SwissADME website and the compounds that met these regulations would be docked to the TIGIT protein using AutoDock Tools and AutoDock Vina. The interactions with the highest binding energies were visualized using BIOVIA Discovery Studio 2020. The test compounds then underwent a toxicity profile analysis on the admetSAR 2.0 website.

Results: All test compounds complied with the Lipinski rule. The molecular docking results showed the highest binding energy in kahweol and cafestol (-8.1 kcal/mol) compared to OMC ( $-7.9 \mathrm{kcal} / \mathrm{mol})$, chlorogenic acid $(-7.8 \mathrm{kcal} / \mathrm{mol})$, caffeic acid $(-6.3 \mathrm{kcal} / \mathrm{mol}), \mathrm{caffeine}(-6.1 \mathrm{kcal} / \mathrm{mol})$, trigonelline $(-5.3 \mathrm{kcal} / \mathrm{mol})$, HMF $(-5.1 \mathrm{kcal} / \mathrm{mol})$, furfuryl alcohol $(-4.4 \mathrm{kcal} / \mathrm{mol})$, and 5 -fluorouracil as the comparator drug $(-5.3 \mathrm{kcal} / \mathrm{mol})$. Kahweol, cafestol, and 5-fluorouracil revealed the hydrophobic interactions and hydrogen bonds with amino acid residues in TIGIT. Kahweol and cafestol unveiled minimal toxicity prediction

Conclusion: Kahweol and cafestol demonstrated the best results in inhibiting the TIGIT protein which played a role in colorectal cancer. In vitro and in vivo studies are needed to strengthen the findings of this research.

Keywords: Colorectal cancer, In silico, Robusta coffee.

(C) 2021 The Authors. Published by Innovare Academic Sciences Pvt Ltd. This is an open access article under the CC BY license (http://creativecommons.org/ licenses/by/4.0/) DOI: http://dx.doi.org/10.22159/ajpcr.2021v14i10.43025. Journal homepage: https://innovareacademics.in/journals/index.php/ajpcr

\section{INTRODUCTION}

Cancer still becomes a big problem in the world of health. In 2018, 18.1 million people in the world experienced cancer and 9.6 million of them died from the disease, so it cannot be denied that it is responsible for $30 \%$ of premature deaths from non-communicable diseases in adults aged 30-69 years. The incidence rate also has the potential to continue to increase to nearly double by 2040 , especially in lower-middleincome countries, including Indonesia [1].

One of the types of cancer with the highest prevalence in Indonesia is colorectal cancer which occupies the $2^{\text {nd }}$ and $3^{\text {rd }}$ position, respectively, as the most common cancer in men and women [2]. The incidence rate of colorectal cancer is associated with various risk factors such as unhealthy diet, lack of physical activity, and excess body weight. In most cases, the initial treatment chosen is surgery which can be accompanied by adjuvant therapy in the form of radiotherapy and chemotherapy [3]. The 5-year survival rate and mortality rate depend on the stage and time of diagnosis [4]. For example, patients with metastatic colorectal cancer who do not undergo surgical resection only have 8 months of life expectancy, whereas a combination of chemotherapy and targeted therapy may prolong the patient's median life expectancy, but long-term therapy can cause long-term adverse effects that reduce the patient's quality of life [5]. Hence, early primary tumor intervention is crucial to improve the patient's outcome [4].

Fusobacterium nucleatum microorganism may have a role in colorectal cancer. F. nucleatum has the virulence factors FadA and Fap2 that help to form a bond with intestinal epithelial cells, when reviewed further, Fap2 has a role in suppressing the immune system and increasing inflammatory cells that play a role in the development of neoplasia [6]. This mechanism is suspected to occur through the binding of Fap2 to the T-cell immunoglobulin and immunoreceptor tyrosine-based inhibitory motif domain (TIGIT) domain receptors, causing the growth and proliferation of cancer cells [7]. Thus, targeting TIGIT is a new option in the management of colorectal cancer.

South Sumatra Province is listed as the main producer of coffee in Indonesia with production reaching 193,507 thousand tons (25.59\%) [8]. Recent findings in two prospective cohort studies suggested that increased coffee intake after a diagnosis of colorectal cancer was associated with a reduced mortality risk, both related to colorectal cancer and other causes. This was related to various pathways such as active substances that suppressed tumor metastasis, maintained low inflammatory status and high insulin sensitivity, and prevented metastases to the liver, the main contributor to colorectal cancer-related deaths [9]

The molecular docking technique has been frequently used to predict the interaction of proteins with drug molecules. This method is essential to determine the accurate prediction of active sites and test ligand structures based on drug design [10]. Therefore, the purpose of this research is to determine the efficacy of the compounds in robusta coffee against colorectal cancer in silico through the inhibition of the TIGIT protein. This research was useful to provide information for the drug industry and further research in humans, especially in colorectal cancer management.

\section{METHODS}

The type of research applied was empirical research using the computational chemistry method (in silico). The methods used in this 
research included molecular docking simulation and toxicity prediction of the test compounds. The test compounds used were caffeine (CID: 2519), caffeic acid (CID: 689043), chlorogenic acid (CID: 1794427), kahweol (CID: 114778), trigonelline (CID: 5570), 16-0-Methylcafestol (OMC; CID: 68103163), cafestol (CID: 108052), furfuryl alcohol (CID: 7361), and 5-Hydroxymethylfurfural (HMF; CID: 237332) with the comparator drug in the form of 5-fluorouracil (CID: 3385) as the colorectal cancer chemotherapeutic agent. The chemical structures of the compound were downloaded from the PubChem website (https://www.pubchem. ncbi.nlm.nih.gov). Meanwhile, the TIGIT protein (PDB ID: 3Q0H) was downloaded from the RCSB PDB website (https://www.rcsb.org).

Lipinski rule is to analyze the drug-like properties or the solubility and absorption of a compound. The compound structures that had been selected would be downloaded from the PubChem compound database in *.sdf format and then analyzed manually by uploading the compound file form to the SMILES format and then uploaded to the SwissADME website (http://www.swissadme.ch/index.php). The test ligands from compounds in coffee that complied with Lipinski rule were prepared by converting the file format using the BIOVIA Discovery Studio 2020 application from *.sdf to ${ }^{*}$ pdb.

The structure of the TIGIT protein downloaded from the Protein Data Bank website was the structure obtained from X-ray experiment (crystal structure) containing the ligands. The protein preparation was carried out using the BIOVIA Discovery Studio 2020 program and Autodock Tools by adding polar hydrogen atoms and separating the active form of the TIGIT protein from its native ligands so a pocket was available as the docking material whose shape and coordinates could be known. The file was then saved in *.pdbqt format.

The molecular docking was performed to predict the molecular binding to the target protein so that the activity and affinity predictions could be known. The test ligands that had met the requirements and had been optimized were docked on the TIGIT protein whose native ligands had been removed using the Autodock Tools application at coordinates and grid boxes according to the validation results. The ligand binding affinity was predicted as a negative Gibbs free energy score $(\Delta G)$ calculated using the AutoDock Vina scoring function. The best and most energetic conformation (lowest binding energy) among each ligand would be selected. The results of the tethering were then saved in a file with *.pdbqt format and converted to *.pdb using PyMOL for 2D and 3D visualization using the BIOVIA Discovery Studio 2020 application to see the interactions that occurred between the test ligands and proteins. The interactions analyzed were hydrogen bonds and hydrophobic interaction.

Finally, the toxicity prediction of the test ligands was carried out using AdmetSAR server 2.0 (http://lmmd.ecust.edu.cn/admetsar2) by inserting the test ligand SMILES file. The compound toxicity assessment components based on Ziemska et al. (2019) research were carcinogenicity, eye corrosion, eye irritation, Ames mutagenesis, hepatotoxicity, and acute oral toxicity [11].

\section{RESULTS AND DISCUSSION}

TIGIT is a receptor located on the surface of lymphocyte cells mainly expressed on the CD8 ${ }^{+}$cell surface. The patients with colorectal cancer showed higher levels of $\mathrm{TIGIT}^{+}$of $\mathrm{CD}^{+}$cell infiltration in metastatic tumor tissue. TIGIT $^{+}$of $\mathrm{CD}^{+}$cell demonstrated expression at low levels for killer cytokines such as IL-2, TNF- $\alpha$, and IFN- $\gamma$ and an increase in the inhibitory receptors such as LAG-3, PD-1, and TIM-3 on the surface of $\mathrm{TIGIT}^{+}$of $\mathrm{CD}^{+}$cell. The accumulation of $\mathrm{TIGIT}^{+}$in $\mathrm{T}$ cells of patients with colorectal cancer was associated with more advanced disease conditions, predictable early recurrence, and decreased survival rates so that TIGIT could be a marker, a prognostic determinant, and a potential target in the colorectal cancer treatment [12]. In the following discussion, the researchers conducted drug-like properties analysis using Lipinski's rule of five and toxicity profile analysis of the test compounds from robusta coffee.

\section{Drug-like properties analysis}

A drug molecule can be considered ideal if it adheres to the guidelines for phytochemical properties of the Lipinski rule of five to predict the drug similarity of a chemical compound with a particular biological activity designed for the oral route of drug administration. According to these rules, drug-like compounds should have a molecular weight (MW) $<500 \mathrm{~g} / \mathrm{mol}$, a $\log \mathrm{p}<5$ (to describe hydrophobicity), several hydrogen bond donors (HBDs) no more than 5 , and several hydrogen bond acceptors (HBAs) no more than 10 [13], with the number of violations allowed no more than 1 [14]. The results of the analysis are shown in Table 1.

Given that no more than 1 violation occurred in the results of the analysis in each compound, it meant that all of them could be excellent candidates for further study and manipulation.

\section{Molecular docking analysis}

The docking simulation of the test compounds in coffee against the TIGIT protein showed that the best binding energy value was in kahweol $(-8,1$ $\mathrm{kcal} / \mathrm{mol})$ and cafestol $(-8,1 \mathrm{kcal} / \mathrm{mol})$ with the comparator drug in the form of 5-fluorouracil $(-5,3 \mathrm{kcal} / \mathrm{mol})$. The complete results that had been sorted from the largest binding energy values are shown in Table 2.

The protein-ligand binding occurred when the Gibbs free energy $(\Delta \mathrm{G})$ is negative at equilibrium at constant temperature and pressure. $\mathrm{G}$ determines the stability of the protein-ligand complex or the binding affinity of the ligand to a particular receptor [15]. A negative G score is significant in determining the drug efficacy [16]. As a result, the compounds in robusta coffee, especially kahweol and cafestol which had the most negative binding energies to TIGIT, were presumed to bind more stable than these compounds.

Furthermore, the visualization of the test compound binds with the TIGIT protein was carried out and images based on the hydrophobic interactions and hydrogen bonds were obtained in Figs. 1-3.

Table 1: Drug-like properties analysis using Lipinski's rule of five

\begin{tabular}{lllllll}
\hline No. & Compounds & $\begin{array}{l}\mathbf{M W}^{\mathrm{a}} \\
\text { (g/mol) }\end{array}$ & alogP $^{\mathbf{b}}$ & $\mathbf{H B A}^{\mathbf{c}}$ & $\mathbf{H B D}^{\mathbf{d}}$ & $\begin{array}{l}\text { Violation } \\
\text { (s) }\end{array}$ \\
\hline 1. & Caffeine & 194.19 & -1.03 & 3 & 0 & 0 \\
2. & Caffeic acid & 180.16 & 1.09 & 4 & 3 & 0 \\
3. & Chlorogenic & 354.31 & -0.75 & 9 & 6 & 1 \\
& acid & & & & & \\
4. & Kahweol & 314.42 & 3.61 & 3 & 2 & 0 \\
5. & Trigonelline & 137.14 & -1.13 & 2 & 0 & 0 \\
6. & OMC & 330.46 & 4.29 & 3 & 1 & 0 \\
7. & Cafestol & 316.43 & 3.64 & 3 & 2 & 0 \\
8. & Furfuryl & 98.10 & 0.62 & 2 & 1 & 0 \\
& alcohol & & & & & \\
9. & HMF & 126.11 & 0.43 & 3 & 1 & 0 \\
10. & 5-fluorouracil & 130.08 & -0.38 & 3 & 2 & 0 \\
\hline
\end{tabular}

Table 2: Binding energy of the test compounds to the TIGIT protein

\begin{tabular}{lll}
\hline No. & Compounds & $\begin{array}{l}\text { Binding energy } \\
\text { (kcal/mol) }\end{array}$ \\
\hline 1. & Kahweol & -8.1 \\
2. & Cafestol & -8.1 \\
3. & OMC & -7.9 \\
4. & Chlorogenic acid & -7.8 \\
5. & Caffeic acid & -6.3 \\
6. & Caffeine & -6.1 \\
7. & Trigonelline & -5.3 \\
8. & HMF & -5.1 \\
9. & Furfuryl alcohol & -4.4 \\
10. & 5-fluorouracil & -5.3 \\
\hline
\end{tabular}


The purpose of visualizing the docking results was to see non-covalent interactions such as hydrogen bonds and hydrophobic interactions between compounds and proteins. This could help in understanding the binding mode, affinity, and orientation of the compounds tethered to the protein active sites [17]. The hydrophobic interaction was a predominant contributor to protein stability so that the hydrophobic bond was the main determinant of the folding configuration balance in most native proteins when compared to the hydrogen bonds [16]. Based on the results in Table 3, various hydrophobic interactions and hydrogen bonds occurred between the test ligands and amino acid residues, including kahweol interacted hydrophobically with amino acid Tyr118 at distances of $4.98 \AA$ and $5.39 \AA ̊$; cafestol interacted with amino acid Tyr118, Leu73, Ile27, Tyr118, and Tyr118 at distances of $4.60 \AA, 5.34 \AA, 5.45 \AA, 5.05 \AA$, and $5.41 \AA$; and 5-fluorouracil interacted with amino acid Leu65, His111, His111, and Ile109 at distances of $3.65 \AA, 4.49 \AA, 4.46 \AA$, and $4.76 \AA$. Accordingly, the most common hydrophobic interaction was found in the amino acid Tyr118 although it was not found in all bonds with the test ligands.

The previous studies had shown that kahweol caused downregulation of D1 cyclin expression in human colorectal cancer cells through proteasomal degradation through Thr26 phosphorylation and transcriptional regulation that might induce anti-cancer effects [18]. In addition, kahweol induced apoptosis through upregulation of activating

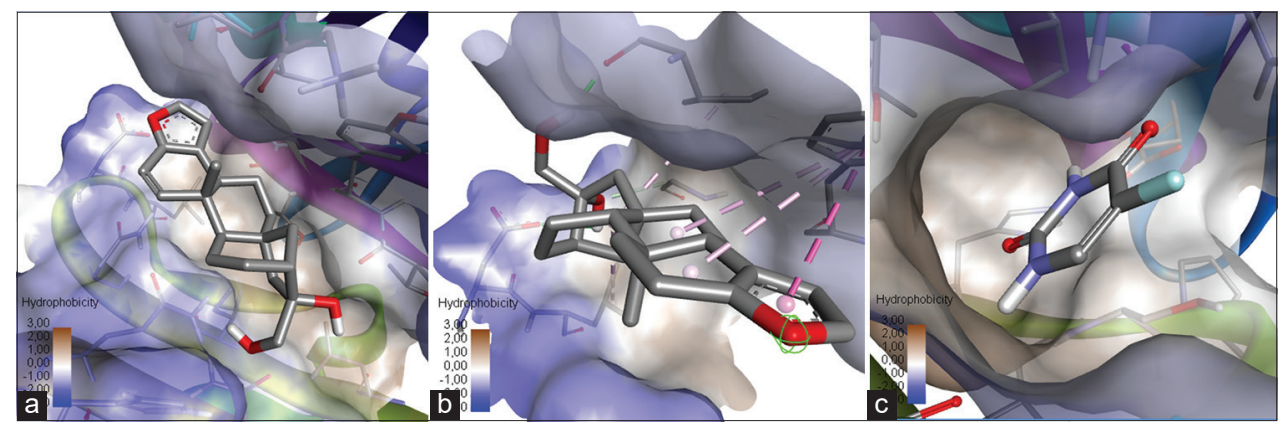

Fig. 1: 3D visualization of molecular docking results based on hydrophobic interactions. (a) Kahweol; (b) cafestol; (c) 5-fluorouracil
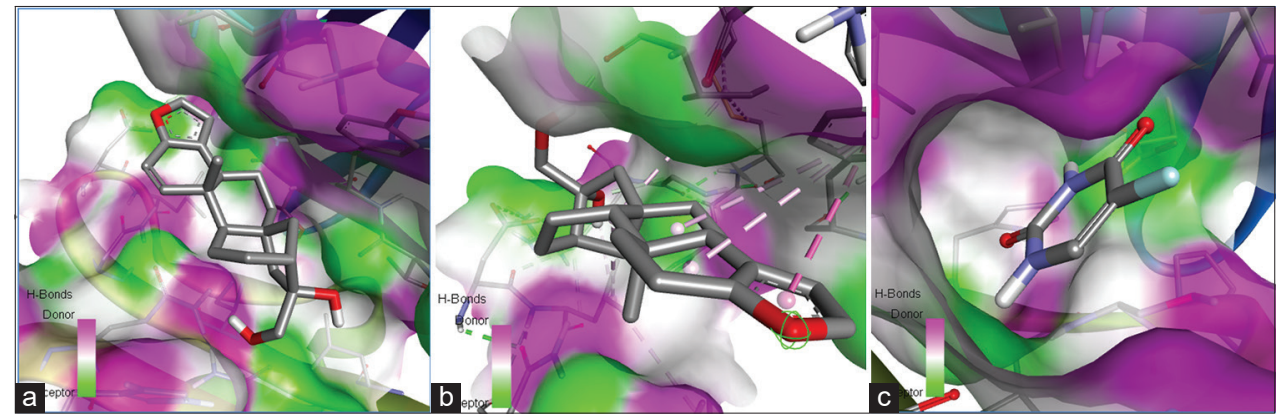

Fig. 2: 3D visualization of molecular docking results based on hydrogen interactions. (a) Kahweol; (b) cafestol; (c) 5-fluorouracil

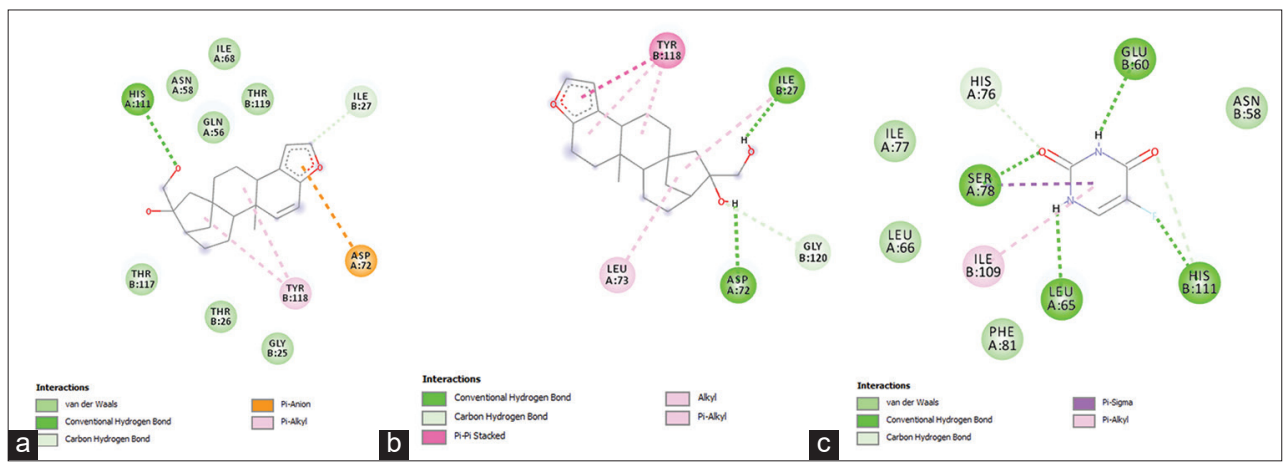

Fig. 3: 2D visualization of molecular docking results. Through this image, it can be seen the types of bonds that occurred between the test compounds and the protein. (a) Kahweol; (b) cafestol; (c) 5-fluorouracil

Table 3: The interactions of the test ligands on amino acid residues at the binding sites to TIGIT

\begin{tabular}{lll}
\hline \multirow{2}{*}{ Ligands } & \multicolumn{2}{l}{ Involved amino acids and the binding distances ( $\mathrm{A})$} \\
\cline { 2 - 3 } & Hydrogen interactions & Hydrophobic interactions \\
\hline Kahweol & His111 (2.62), Ile27 (3.47) & Tyr118 (4.98), Tyr118 (5.39) \\
Cafestol & Asp72 (2.57), Ile27 (1.98), Gly120 (3.68) & Tyr118 (4.60), Leu73 (5.34), Ile27 (5.45), Tyr118 (5.05), \\
5-fluorouracil & Ser78 (2.59), Gln64 (3.71), Ile77 (3.30) & Tyr118 (5.41) \\
\hline
\end{tabular}


Table 4: The results of the toxicity profile analysis of the test compounds

\begin{tabular}{|c|c|c|c|c|c|c|c|}
\hline No & Compounds & Carcinogenicity & $\begin{array}{l}\text { Eye } \\
\text { erosion }\end{array}$ & $\begin{array}{l}\text { Eye } \\
\text { irritation }\end{array}$ & $\begin{array}{l}\text { Ames } \\
\text { mutagenesis }\end{array}$ & Hepatotoxicity & $\begin{array}{l}\text { Acute oral } \\
\text { toxicity }\end{array}$ \\
\hline 1. & Caffeine & $-(0.9429)$ & $-(0.9849)$ & $-(0.9515)$ & $-(0.8800)$ & $+(0.6500)$ & II (0.7405) \\
\hline 2. & Caffeic acid & $-(0.8018)$ & $-(0.6303)$ & $+(1.0000)$ & $-(0.9100)$ & $-(0.6750)$ & IV $(0.5588)$ \\
\hline 3. & Chlorogenic acid & $-(0.9292)$ & $-(0.9899)$ & $-(0.8986)$ & $-(0.9900)$ & $-(0.5750)$ & III $(0.7775)$ \\
\hline 4. & Kahweol & $-(0.8429)$ & $-(0.9897)$ & $-(0.9863)$ & $-(0.7100)$ & $-(0.7750)$ & III $(0.5575)$ \\
\hline 5. & Trigonelline & $-(0.6602)$ & $-(0.8164)$ & $+(0.9809)$ & $-(0.8200)$ & $-(0.6750)$ & IV $(0.4690)$ \\
\hline 6. & OMC & $-(0.8857)$ & $-(0.9880)$ & $-(0.9848)$ & $-(0.7000)$ & $-(0.7000)$ & III (0.6023) \\
\hline 8. & Furfuryl alcohol & $-(0.8286)$ & $+(0.7252)$ & $+(0.9749)$ & $-(0.8300)$ & $-(0.8750)$ & II (0.7493) \\
\hline 9. & HMF & $-(0.8714)$ & $+(0.7124)$ & $+(0.9899)$ & $-(0.6200)$ & $-(0.7000)$ & III (0.7997) \\
\hline 10. & 5-fluorouracil & $-(0.8571)$ & $-(0.9835)$ & $+(0.6907)$ & $-(0.6400)$ & $+(0.7500)$ & III (0.4387) \\
\hline
\end{tabular}

transcription factor 3 (ATF3) in human colorectal cancer cells. Increased expression of ERK1/2 or GSK3 $\beta$-dependent ATF3 occurred through transcriptional regulation and kahweol responsible promoter regions between the -147 and -85 regions. In these regions, fushi tarazu (Ftz) and CREB were reported to be cis-acting elements and kahweol was thought to induce CREB phosphorylation [19].

The anti-carcinogenesis effect has been shown in various studies, especially in renal carcinoma in vitro. Cafestol levels were positively correlated to the inhibition of proliferation and induced apoptosis in Caki cells through the downregulation of anti-apoptotic protein expression, mitochondrial membrane potential levels, cytochrome c release, and inhibition of PI3K/Akt pathway [20]. Cafestol also sensitized ABT-737-mediated apoptosis through the downregulation of Mcl-1 expression and upregulation of Bim expression in renal Caki cells so that it was presumed to be effective in treating solid tumors [21].

\section{Toxicity profile analysis}

Toxicity profiles of the compounds are shown in Table 4. From the results of the toxicity test, it was found that all substances did not show the potential carcinogenicity of eye erosion, and Ames mutagenesis. However, caffeic acid, trigonelline, furfuryl alcohol, HMF, and 5-fluorouracil exhibited potential eye irritation. In terms of hepatotoxicity, only caffeine and 5-fluorouracil had this potential. In terms of acute oral toxicity class, the substances were grouped into four categories based on the WHO criteria. Category I consisted of substances with $\mathrm{LD}_{50}$ of $\leq 50 \mathrm{mg} / \mathrm{kg}$. Category II consisted of substances with $\mathrm{LD}_{50}$ of $>50 \mathrm{mg} / \mathrm{kg}$ to $<500 \mathrm{mg} / \mathrm{kg}$. Category III consisted of substances with $\mathrm{LD}_{50}$ of $>500 \mathrm{mg} / \mathrm{kg}$ to $<5000 \mathrm{mg} / \mathrm{kg}$. Category IV consisted of substances with $\mathrm{LD}_{50}$ of $>5000 \mathrm{mg} / \mathrm{kg}$ [22]. Six of the 10 substances, namely, chlorogenic acid, kahweol, OMC, cafestol, HMF, and 5-fluorouracil were in Class III; two of the 10 substances, namely, caffeic acid and trigonelline were in Class IV; finally, caffeine and furfuryl alcohol were in Class II.

Overall, starting from potential carcinogenicity, eye erosion, eye irritation, Ames mutagenesis, hepatotoxicity, and acute oral toxicity, chlorogenic acid, kahweol, OMC, and cafestol showed less potency. These results provided basic data regarding the toxicity profile of the test compounds and could assist in determining the appropriate route of administration, form, and dose. Nonetheless, these various probability values indicated that these studies were fundamental and should be confirmed experimentally.

\section{CONCLUSION}

Kahweol and cafestol were the compounds in robusta coffee that demonstrated the best results in inhibiting the TIGIT protein which played a role in the course of colorectal cancer. Further studies are needed at the in vitro and in vivo levels to strengthen the findings of this research.

\section{ACKNOWLEDGMENT}

This research is supported by the Directorate of Learning and Student Affairs, Ministry of Education and Culture of the Republic of Indonesia through the 2021 Student Creativity Program.

\section{AUTHORS' CONTRIBUTIONS}

Dessy Agustini, Leo Vernadesly, and Delviana concept the research, collect and analyze the data, and write the manuscript. Theodorus contributes as a supervisor by providing feedback for the research and manuscript.

\section{CONFLICTS OF INTEREST}

All authors declared that there were no conflicts of interest.

\section{AUTHORS' FUNDING}

The 2021 Student Creativity Program funds this research.

\section{REFERENCES}

1. World Health Organization. WHO Report on Cancer: Setting Priorities, Investing Wisely and Providing Care for All. Geneva: World Health Organization; 2020.

2. Indonesian Cancer Foundation. Buletin HARPA. $2^{\text {nd }}$ ed. Jakarta: Indonesian Cancer Foundation; 2018.

3. Brenner $\mathrm{H}$, Chen $\mathrm{C}$. The colorectal cancer epidemic: Challenges and opportunities for primary, secondary and tertiary prevention. Br J Cancer 2018;119:785-92

4. Koncina E, Haan S, Rauh S, Letellier E. Prognostic and predictive molecular biomarkers for colorectal cancer: Updates and challenges. Cancers (Basel) 2020;12:319.

5. Zhu H, Hao J, Niu Y, Liu D, Chen D, Wu X. Molecular targets of Chinese herbs: A clinical study of metastatic colorectal cancer based on network pharmacology. Sci Rep 2018;8:1-12.

6. Sun $\mathrm{CH}$, Li BB, Wang B, Zhao J, Zhang XY, Li TT, et al. The role of Fusobacterium nucleatum in colorectal cancer: From carcinogenesis to clinical management. Chronic Dis Transl Med 2019;5:178-87.

7. Guevarra LA Jr., Afable AC, Belza PJ, Dy KJ, Lee SJ, Sy-Ortin TT, et al. Immunogenicity of a Fap2 peptide mimotope of Fusobacterium nucleatum and its potential use in the diagnosis of colorectal cancer. Infect Agent Cancer 2018;13:11.

8. Central Bureau of Statistics Indonesia. Statistik Kopi Indonesia 2019. Jakarta: Badan Pusat Statistik Republik Indonesia; 2019.

9. Hu Y, Ding M, Yuan C, Wu K, Smith-Warner SA, Hu FB, et al. Association between coffee intake after diagnosis of colorectal cancer and reduced mortality. Gastroenterology 2018;154:916-26.e9.

10. Muthu S, Durairaj B. Molecular docking studies on interaction of Annona muricata compounds with antiapoptotic proteins $\mathrm{Bcl}-2$ and survivin. Sky J Biochem Res 2016;5:14-7.

11. Ziemska J, Solecka J, Jarończyk M. In silico screening for novel leucine aminopeptidase inhibitors with 3,4-dihydroisoquinoline scaffold. Molecules 2020;25:1753.

12. Liang R, Zhu X, Lan T, Ding D, Zheng Z, Chen T, et al. TIGIT promotes $\mathrm{CD} 8^{+} \mathrm{T}$ cells exhaustion and predicts poor prognosis of colorectal cancer. Cancer Immunol Immunother 2021;70:2781-93

13. Chen X, Li H, Tian L, Li Q, Luo J, Zhang Y, Analysis of the physicochemical properties of acaricides based on Lipinski's rule of five. J Comput Biol 2020;27:1397-406.

14. Doak BC, Over B, Giordanetto F, Kihlberg J. Oral druggable space beyond the rule of 5: Insights from drugs and clinical candidates. Chem Biol 2014;21:1115-42

15. Du X, Li Y, Xia YL, Ai SM, Liang J, Sang P, et al. Insights into proteinligand interactions: Mechanisms, models, and methods. Int J Mol Sci 2016;17:144. 
16. Afriza D, Suriyah WH, Ichwan SJ. In silico analysis of molecular interactions between the anti-apoptotic protein survivin and dentatin, nordentatin, and quercetin. J Phys Conf Ser 2018;1073:1-7.

17. Dhurga K, Gunasekaran G, Senthilraja P, Manivel G, Stalin A. Molecular modeling and docking analysis of pseudomonal bacterial proteins with eugenol and its derivatives. Res J Life Sci Bioinform Pharm Chem Sci 2016;2:40-50.

18. Park GH, Song HM, Jeong JB. The coffee diterpene kahweol suppresses the cell proliferation by inducing cyclin D1 proteasomal degradation via ERK1/2, JNK and GKS3 $\beta$-dependent threonine-286 phosphorylation in human colorectal cancer cells. Food Chem Toxicol 2016;95: 142-8

19. Park GH, Song HM, Jeong JB. Kahweol from coffee induces apoptosis by upregulating activating transcription factor 3 in human colorectal cancer cells. Biomol Ther 2017;25:337-43.

20. Choi MJ, Park EJ, Oh JH, Min KJ, Yang ES, Kim YH, et al. Cafestol, a coffee-specific diterpene, induces apoptosis in renal carcinoma Caki cells through down-regulation of anti-apoptotic proteins and Akt phosphorylation. Chem Biol Interact 2011;190:102-8

21. Woo SM, Min KJ, Seo BR, Nam JO, Choi KS, Yoo YH, et al. Cafestol overcomes ABT-737 resistance in Mcl-1-overexpressed renal carcinoma Caki cells through downregulation of Mcl-1 expression and upregulation of Bim expression. Cell Death Dis 2014;5:e1514.

22. Ammar O. In silico pharmacodynamics, toxicity profile and biological activities of the Saharan medicinal plant limoniastrum feei. Braz J Pharm Sci 2017;53:1-10. 